\title{
Use of the Pessary in the Prevention of Preterm Delivery
}

\section{Uso do pessário na prevenção de parto pretermo}

\author{
Thayane Delazari Corrêa ${ }^{1}$ Ester Gomes Amorim1 Jade Aimée Guimarães Tomazelli ${ }^{1}$ \\ Mário Dias Corrêa Júnior ${ }^{10}$ \\ ${ }^{1}$ Departament of Obstetrics and Gynecology, Universidade Federal de \\ Minas Gerais, Belo Horizonte, MG, Brazil \\ Rev Bras Ginecol Obstet 2019;41:53-58. \\ Address for correspondence Mário Dias Corrêa Júnior, MD, PhD, \\ Departamento de Obstetrícia e Ginecologia, Universidade Federal de \\ Minas Gerais, Av. Prof. Alfredo Balena, 110, 30130-100, Santa Efigênia, \\ Belo Horizonte, MG, Brazil (e-mail: correajr@gmail.com).
}

\begin{abstract}
Keywords

- pessary

- preterm birth

- delivery

- premature

- short cervix
\end{abstract}

\section{Resumo}

\section{Palavras-chave}

- pessário

- nascimento prematuro

- parto

- prematuridade

- colo curto
Objective The gestational complication most associated with perinatal mortality and morbidity is spontaneous preterm birth with gestational age $<37$ weeks. Therefore, it is necessary to identify its risk factors and attempt its prevention. The benefits of the pessary in prematurity are under investigation. Our objective was to analyze the use of the pessary in the prevention of preterm births in published studies, and to compare its efficacy with other methods.

Methods Randomized clinical trials published between 2010 and 2018 were selected from electronic databases. Studies on multiple gestations were excluded.

Results Two studies were in favor of the pessary as a preventive method, one study was contrary to the method and another two showed no statistically significant difference. The meta-analysis showed no statistical difference with the use of a cervical pessary in the reduction of births $<37$ (odds ratio [OR]: 0.63; confidence interval [95\% $\mathrm{Cl}$ ]: 0.38-1.06) and < 34 weeks (OR: 0.74; 95\% Cl: 0.35-1.57)

Conclusion The pooled data available to date seems to show a lack of efficacy of the cervical pessary in the prevention of preterm birth, although the heterogeneity of the studies made comparisons more difficult.

Objetivo O parto com idade gestacional < 37 semanas é a complicação gestacional mais associada à mortalidade e morbidade perinatal, sendo necessária a identificação de seus fatores de risco e a tentativa de sua prevenção. Os benefícios do pessário na prematuridade estão sendo investigados. Nosso objetivo foi analisar os estudos publicados sobre uso do pessário na prevenção do parto pretermo e comparar sua eficácia perante outros métodos.

Métodos Foram selecionados estudos clínicos randomizados publicados entre $2010 \mathrm{e}$ 2018, extraídos de bases eletrônicas de dados. Estudos de gestações múltiplas foram excluídos.

Resultados Dois estudos se mostraram a favor do pessário como método preventivo, um estudo foi contrário ao método, e outros dois não demonstraram diferença estatisticamente significativa. A meta-análise não mostrou diferença significativa no

(1) ORCID ID is https://orcid.org/0000-0003-4198-0546.

received

August 15, 2018

accepted

October 22, 2018
DOI https://doi.org/

10.1055/s-0038-1676511. ISSN 0100-7203.
Copyright $\odot 2019$ by Thieme Revinter

Publicações Ltda, Rio de Janeiro, Brazil
License terms

(c) (1) 
uso do pessário na redução de nascimentos < 37 (razão de chance [RC]: 0,63; intervalo de confiança [IC 95\%]: 0,38-1,06) e < 34 semanas (RC: 0,74; IC 95\%: 0,35-1,57). Conclusão Os dados agrupados disponíveis até o momento parecem mostrar uma falta de eficácia do pessário cervical na prevenção do parto pretermo, embora a heterogeneidade dos estudos tenha dificultado as comparações.

\section{Introduction}

Nearly 15 million preterm births occur annually worldwide. Delivery at a gestational age $<37$ weeks is the gestational complication more closely associated with perinatal mortality and morbidity. ${ }^{1}$ Children born prematurely still have a high risk of complications and hospital readmissions throughout life. ${ }^{2,3}$

The etiology of preterm birth is multifactorial, and the history of preterm delivery is the most significant risk factor. Another important factor is the presence of a short cervix ( $<$ $25 \mathrm{~mm}$ ) identified by transvaginal ultrasonography between 20 and 24 weeks of gestation. 2,4

A large reduction in mortality rates and in neonatal morbidity resulting from preterm deliveries will only be achieved with greater accuracy after the proper identification of women with risk factors for this complication and the development of efficient prevention strategy. ${ }^{2}$

One of the prevention strategies considered is the use of progesterone. Progesterone acts reducing the contractions of the uterine smooth muscle and decreasing the inflammatory process involved in the onset of labor. Progesterone is considered a key hormone for pregnancy maintenance, and if a decline of progesterone action occurs in the midtrimester, cervical shortening may occur, which would predispose the patient to preterm delivery. A blockade of progesterone action can lead to the clinical, biochemical and morphologic changes associated with cervical ripening. ${ }^{5}$ Progesterone has been shown to be effective in reducing the preterm delivery and neonatal mortality rates when compared with placebo. ${ }^{3,4}$
Cervical cerclage is a surgical procedure first introduced by Shirodkar and McDonald in the mid-1950s, currently used prophylactically for women with second-trimester repetitive loss suggestive of cervical insufficiency. A history of previous preterm birth and of cervical changes in the ongoing gestation indicated by ultrasonography (cervical length $<25 \mathrm{~mm}$ before 24 weeks) and altered physical examination (cervical dilatation perceived in the physical examination before 24 weeks) are also recognized indications in the literature. Cervical cerclage consists of a suture of the uterine cervix, performed preferably at the beginning of the gestation (8-14 weeks), which acts as a physical barrier, as well as a biochemical one, by protecting the membranes from ascending pathogens. ${ }^{2,6}$

An alternative approach could be the pessary, which is a device that has been used for the past 50 years. ${ }^{7}$ The pessary is a conical ring of silicone that is introduced inside the vagina until it encircles the entire cervix, closing the cervical canal and preventing its dilatation or shortening. ${ }^{1,8,9}$ It promotes a change in the cervical angle, reducing the direct pressure of the uterine contents in the canal, and may be a safer alternative to surgical cerclage because it is easily removable and does not require anesthesia. ${ }^{3,7,9}$ This device can be used from the diagnosis of a short cervix, usually around between 18 and 22 weeks of gestation, and is withdrawn by the obstetrician at between 36 and 37 weeks of gestation, at which age the fetus has better clinical and physiological conditions for survival. ${ }^{7}$

The ARABIN Cerclage Pessar Perforiert pessary (Dr. Arabin $\mathrm{GmbH} \&$ Co., Witten, Germany) ${ }^{10}$ has three different diameters to better suit the uterine cervix. It has been

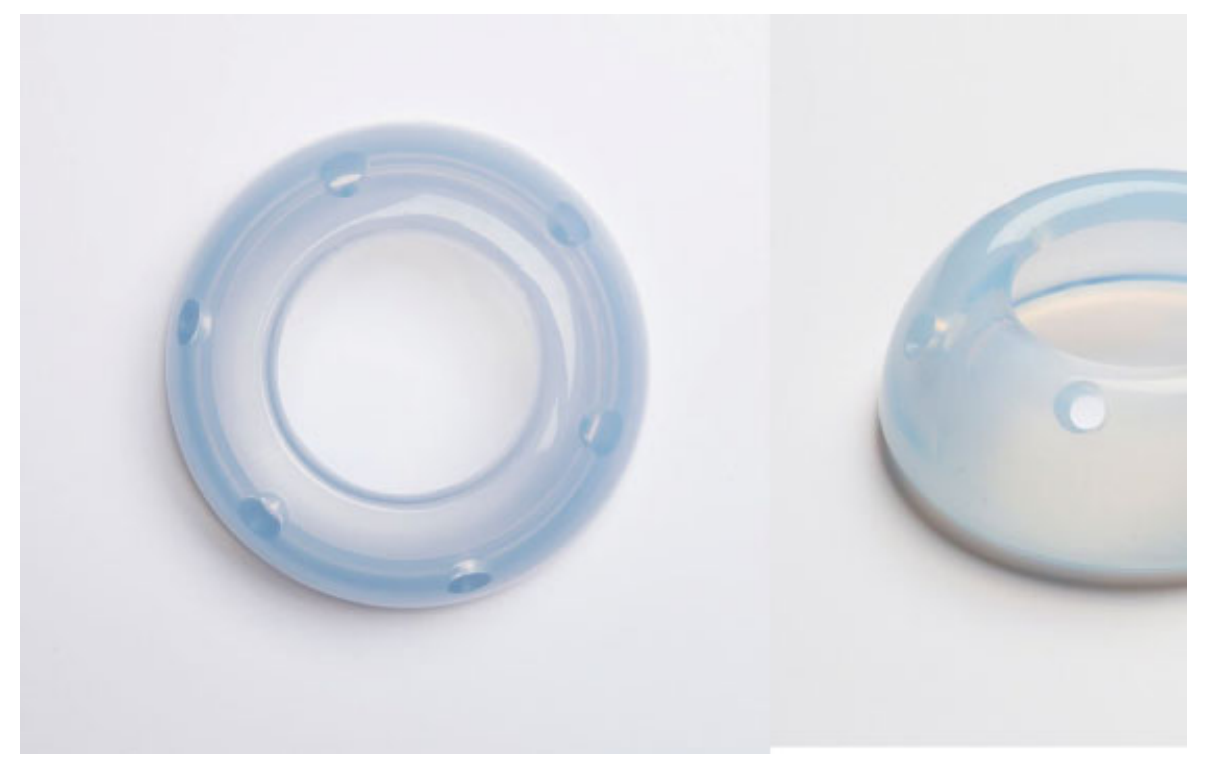

Fig. 1 Picture of the ARABIN Cerclage Pessar Perforiert pessary. ${ }^{10}$ 


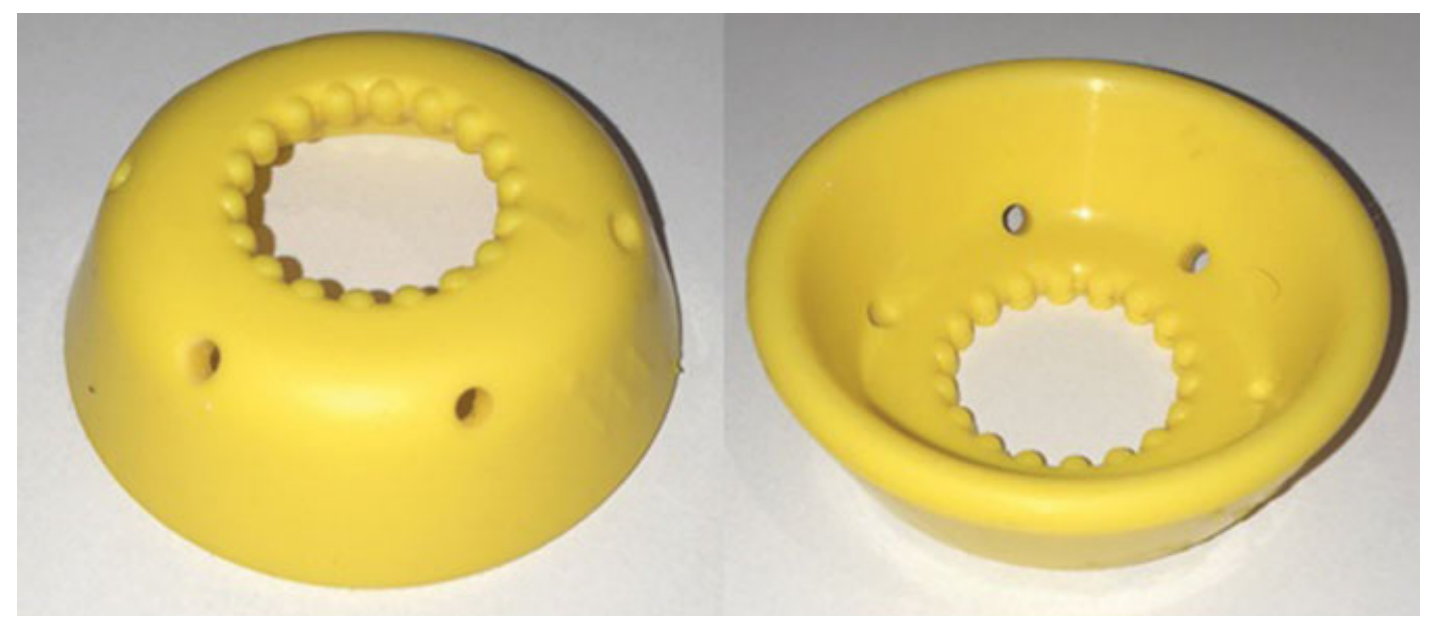

Fig. 2 Picture of the PESSÁRIO AM INGÁMED ${ }^{11}$.

released for use in Brazil about two years ago and we have an authorized representative in Brazil (-Fig. 1). The AM Ingámed pessary (Ingámed, Maringá, PR, Brazil) ${ }^{11}$ is developed by a Brazilian company, made of silicone in order to better adapt to the cervix (-Fig. 2). We do not have studies comparing the differences between the two types. In Brazil, the P5 study is underway to compare vaginal progesterone versus pessary and progesterone in patients with short cervix diagnosed by ultrasound, using the Ingámed pessary. The use of a cervical pessary in conjunction with intravaginal progesterone is shown to be a safe and feasible method for the prevention of preterm birth in women with a short midtrimester cervix. Moreover, this combined treatment has led to a pregnancy prolongation of $\sim 13.5$ weeks, according to recent studies. ${ }^{12}$

Since it is a less invasive preventive method than cerclage, not dependent on hormonal supplementation, the pessary is assuming an important role in the medical practice among obstetricians. ${ }^{2}$ The present article aims to review the latest advances in the efficacy of this method in the management of patients at risk of preterm birth.

\section{Methods}

Trials were identified by searching the literature in the PubMed, Scielo, EMBASE and Cochrane databases, between 2010 and 2018. The keywords used were pessário and pessário cervical and their correspondents in English, pessary and cervical pessary. The inclusion criteria were: articles with randomized controlled trials randomized clinical trials (RCTs) that evaluated the use of the pessary in the prevention of preterm births. Twenty-eight articles were found, and the ones that did not meet the criteria of the present study were excluded. The exclusion criteria were: articles published outside the period described, and those referring to the use of pessaries in multiple gestations.

The final review was based on 5 articles from RCTs analyzing the efficacy of the pessary in preventing preterm birth in single pregnancies, in which the expected primary $\geq 34$ and $\geq 37$ weeks.
The assessment of the quality of the included studies and of their risk of bias was performed according to the criteria outlined in the Cochrane Handbook for Systematic Reviews of Intervention. ${ }^{13}$ The results are shown on - Fig. 3.

Two types of comparisons were made among these publications:

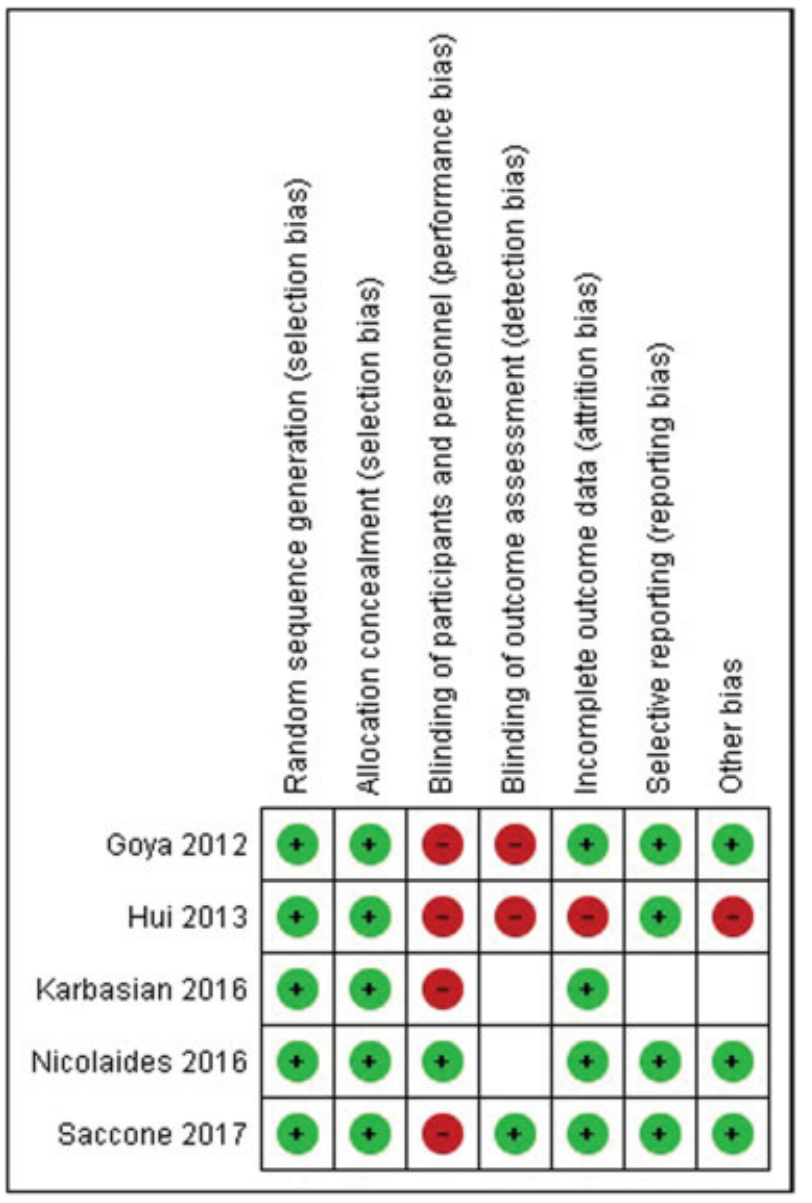

Fig. 3 Summary of the risk of bias for each trial: minus sign: high risk of bias; plus sign: low risk of bias; blank space: unclear risk of bias. 


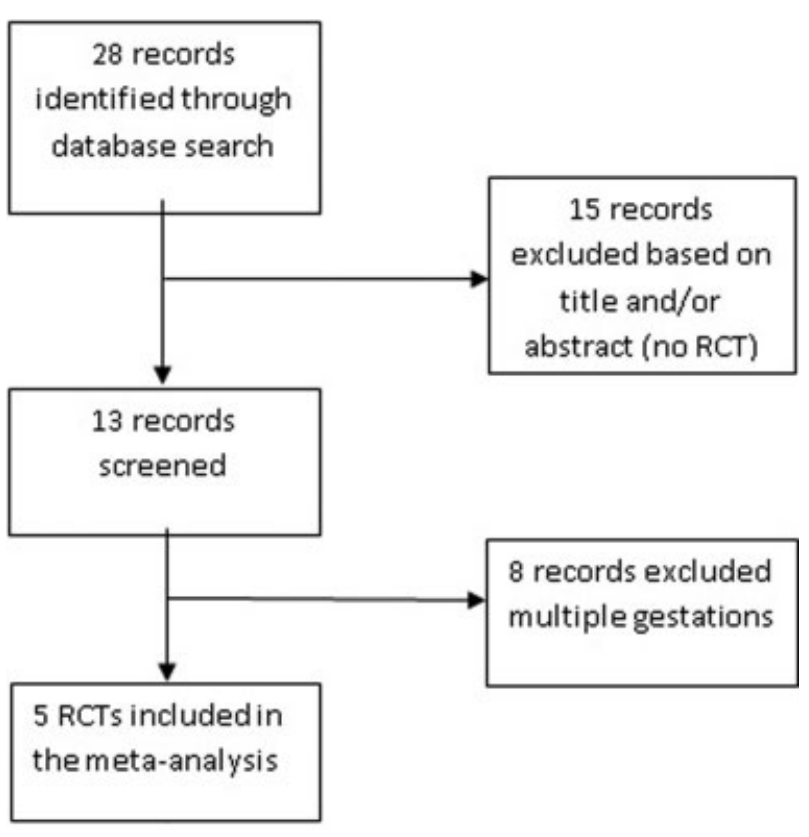

Fig. 4 Flow diagram of identified studies.

1) Vaginal progesterone versus pessary associated with vaginal progesterone.

2) Pessary versus expectant management.

The data analysis was completed independently by two authors (Corrêa Júnior, M. D., and Corrêa T. D.), using the Review Manager (RevMan), Version 5 software (Cochrane Collaboration, Copenhagen, Denmark). The summary measures were reported as relative risk (RR) with a $95 \%$ confidence interval $(\mathrm{CI})$.

\section{Results}

-Fig. 4 shows the flow diagram of the information through the different phases of the review. Thirteen studies were screened; eight trials including multiple gestations were excluded. Five RCTs were therefore included in the metaanalysis.

Blinding was considered not methodologically feasible, given the type of intervention, and none of the studies included was double-blinded. All of the five studies used the ARABIN Cerclage Pessar Perforiert. ${ }^{10}$
Two studies, Saccone et al $(2017)^{1}$ and Karbasian et al $(2016)^{4}$ compared the association of the pessary with vaginal progesterone with the use of progesterone alone. Although the studies have similar outlines, their results were different. Saccone et al $(2017)^{1}$ observed a twofold lower preterm delivery rate with pessary use than in the progesterone-only group ( $7.3 \%$ for pessary associated with progesterone, and $15 \%$ for progesterone).

Karbasian et al (2016) ${ }^{4}$ did not observe a statistically significant difference in the preterm delivery rates between the two groups ( $19.7 \%$ for pessary associated with progesterone, and $16.4 \%$ for progesterone alone).

Studies comparing the use of pessary with expectant management also showed different outcomes. Nicolaides et al (2016) $)^{3}$ did not observe statistically significant differences when comparing the use of the pessary with expectant management ( $12 \%$ of premature parturition with pessary use, and $10.8 \%$ without any intervention).

Hui et al $(2013)^{9}$ observed a $4.1 \%$ higher rate in the outcome of births before 34 weeks with the use of the pessary (9.4\% in the pessary group, and $5.5 \%$ in the control group).

On the other hand, Goya et al $(2012)^{2}$ observed in their study a 4.5 -fold lower rate of preterm delivery with pessary use versus expectant behavior ( $6 \%$ and $27 \%$ of births before 34 weeks, respectively).

It is important to note that, in all of the studies, there was no significant difference between maternal or infant perinatal morbidity and mortality rates as a function of the choice of prevention method.

Vaginal discharge as the main side effect was found in four studies. Goya et al $(2012)^{2}$ observed $100 \%$ of vaginal discharge in the cervical pessary group, and $46 \%$ in the expectant management group. Hui et al $(2013)^{9}$ observed $47 \%$ of vaginal discharge in the cervical pessary group, and $21.8 \%$ in the control group. Nicolaides et al $(2016)^{3}$ observed vaginal discharge in $46.8 \%$ of the pessary group versus $13.8 \%$ of the control group, and a high vaginal swab was obtained for bacteriologic examination; if the results showed infection, appropriate antibiotic therapy was administered. Saccone et al (2017) found vaginal discharge as a side effect in $8.7 \%$ of the pessary group, and in $46 \%$ of the control group. Karbasian et al (2016) ${ }^{4}$ do not describe vaginal discharge as a side effect. - Table 1 summarizes the main findings of the analyzed studies.

The comparison between these studies is difficult due to the methodologies used: pessary versus absence of

Table 1 Main results of the analyzed studies

\begin{tabular}{|l|l|l|l|l|l|}
\hline Author & \multirow{2}{*}{$\mathrm{N}$} & \multicolumn{2}{|l|}{ Prematurity rate } & \multirow{2}{*}{ RR } \\
\cline { 3 - 5 } & & Pessary & Control & \\
\hline Goya et al $(2012)^{2}$ & 380 & $6 \%$ & $27 \%$ & $0.18(0.08-0.37)$ & $<0.0001$ \\
\hline Hui et al $(2013)^{9}$ & 108 & $9.4 \%$ & $5.5 \%$ & $1.04(0.94-1.12)$ & 0.46 \\
\hline Karbasian et al $(2016)^{4}$ & 144 & $19.7 \%$ & $16.4 \%$ & $1.20(0.60-2.41)$ & 0.60 \\
\hline Nicolaides et al $(2016)^{3}$ & 924 & $12 \%$ & $10.8 \%$ & $1.12(0.75-1.69)$ & 0.57 \\
\hline Saccone et al $(2017)^{1}$ & 300 & $7.3 \%$ & $15.3 \%$ & $0.48(0.24-0.95)$ & 0.04 \\
\hline
\end{tabular}

Abbreviation: RR, relative risk. 


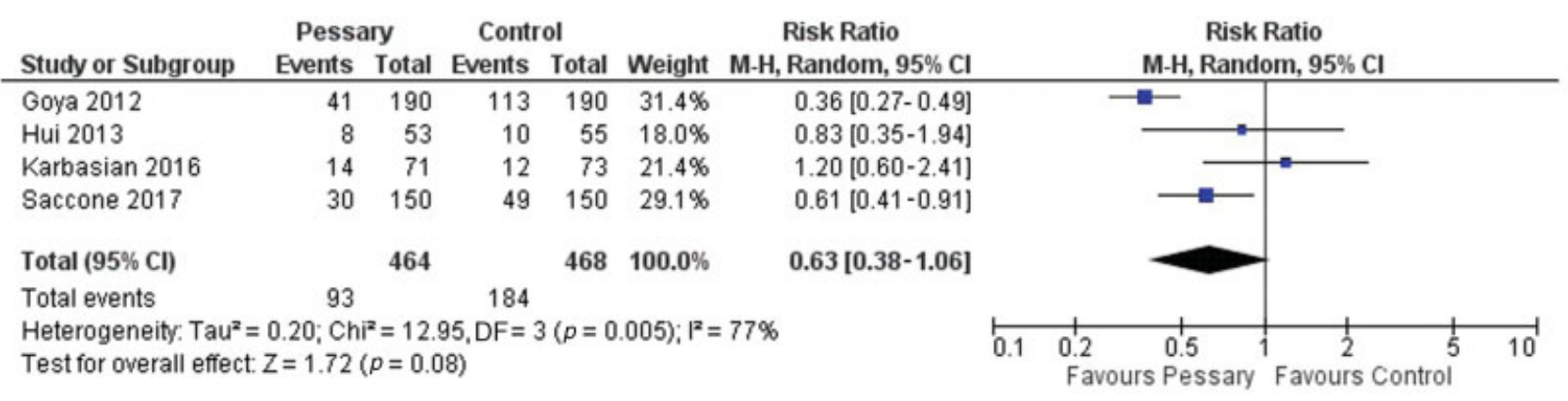

Fig. 5 Meta-analysis of included studies for delivery $<37$ weeks.

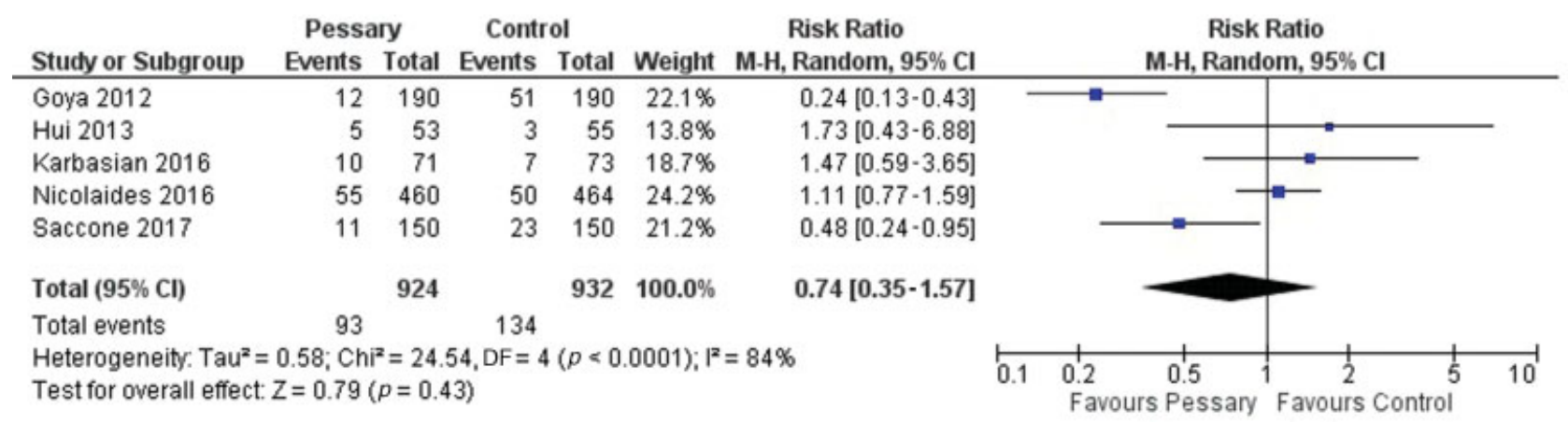

Fig. 6 Meta-analysis of included studies for delivery $<34$ weeks.

intervention or vaginal progesterone. This difficulty is even greater when we consider that progesterone was also used in the group randomized to the use of the pessary in some studies, at the discretion of the attending physician. With this limitation in mind, we have performed a meta-analysis of the included studies, as shown in - Figs. 5 and $\mathbf{6}$.

The meta-analysis showed no statistically significant difference in the use of the pessary with or without the association of vaginal progesterone compared with the group that did not use the pessary when the birth is $<37$ weeks (RR: 0.63; 95\% CI: 0.38-1.06), or $<34$ weeks (RR: 0.74; 95\% CI: 0.35-1.57).

\section{Discussion}

Goya et al $(2012)^{2}$ and Saccone et al $(2017)^{1}$ obtained different results, concluding that the pessary could prevent preterm birth in a population of at-risk women, suitably selected by cervical screening on transvaginal ultrasonography performed during prenatal care obtained similar results. However, in the study by Goya et al, only $11 \%$ of the population was at high risk of spontaneous preterm birth due to previous history.

The divergence between the studies by Nicolaides et al $(2016)^{3}$ and by Saccone et al (2017) $)^{1}$ raise the question of whether cervical pessaries can only be effective at a very low cervix length cutoff, since the mean cervical length in the study by Saccone et al (2017), ${ }^{1}$ which demonstrated a favorable outcome to the use of the pessary, was $\sim 12 \mathrm{~mm}$, whereas in the study by Nicolaides et al (2016), ${ }^{3}$ the mean cervical length was $\sim 20 \mathrm{~mm}$. In addition, the use of progesterone in the study by Nicolaides et al $(2016)^{3}$ in pregnant women with cervical length $\leq 15 \mathrm{~mm}$ may have attenuated the benefit of the pessary in this group.

There were more women with previous preterm deliveries (16.5\%) in the study by Nicolaides et al (2016), ${ }^{3}$ compared with the study by Goya et al $(2012)^{2}(10.8 \%)$, which raises the question of whether the pessary can be effective only in women with a short cervix, but without a prior preterm delivery history. However, this issue could not be further analyzed due to the the fact that none of these trials reported prior spontaneous preterm birth or no prior spontaneous preterm birth as subgroups.

Saccone et al (2017) ${ }^{1}$ performed the only trial involving women with asymptomatic singleton pregnancies without prior spontaneous preterm birth, but with short cervical length detected by transvaginal ultrasound. The other four studies analyzed the same sample of patients with and without a history of prematurity, which may have influenced their outcome.

The differences presented between the analyzed studies show that a better evaluation is necessary before we generalize the favorable outcome of the pessary in the reduction of preterm delivery, considering, for example, low-risk women or different ethnic groups in the analysis.

For example, a more in-depth assessment is needed to clarify whether the study by Goya et al $(2012)^{2}$ recruited women with additional risk factors that could be responsible for such a high baseline preterm rate (27\%) compared with the study by Hui et al $(2013)^{9}(9.4 \%)$. Perhaps the differences in the basal characteristics of the participating women could clarify this question. 
Similarly to our analysis, a systematic review and metaanalysis by Saccone et al $(2017)^{14}$ found that the ARABIN Pessary ${ }^{10}$ does not reduce the rate of spontaneous preterm delivery or improve the perinatal outcome, despite not having included the two studies included our analysis improve the perinatal outcome.

The cervical pessary was not associated with any harmful effects but was associated with a higher rate of vaginal discharge. Although significantly more patients in the pessary group commonly reported side effects, especially an increase in vaginal discharge, the rates of cervicovaginal infection did not differ significantly between the groups in the study by Nicolaides et al (2016), ${ }^{3}$ which was the only trial that used a high vaginal swab for bacteriological examination.

According to Alfirevic et al (2013), ${ }^{15}$ cerclage, vaginal progesterone, and the pessary appear to have similar effectiveness as management strategies in women with a singleton pregnancy, previous spontaneous preterm birth, and a short cervix. However, Norman et al $(2016)^{16}$ performed the largest randomized trial of vaginal progesterone for the prevention of preterm birth in high-risk women, and found no difference between vaginal progesterone and placebo, concluding that the efficacy of progesterone in improving outcomes is either non-existent or weak. However, this study included a very heterogeneous group of patients and was underpowered to detect a meaningful difference. In another study performed by Hassan et al (2011), ${ }^{17}$ it was found that the administration of vaginal progesterone to women with a short cervix was associated with a reduction in the rate of preterm delivery $<33$ weeks, $<35$ weeks, and $<28$ weeks of gestation. Although there is a small number of publications on the use of the pessary, with a diversity of results, indicating the need for more research, the use of this nonhormonal, accessible, and less invasive method for the pregnant woman, which is easily removable when necessary, has been gaining space in the medical practice. ${ }^{1,18}$

\section{Conclusion}

From the analyzed studies, we can conclude that the cervical pessary seems to show a lack of efficacy in the prevention of preterm birth. However, it is not possible to determine its inferiority in the reduction of preterm births when compared with other methods due to the heterogeneity of the existing studies. Its association with progesterone also requires a better evaluation.

Conflicts of Interest

The authors have no conflicts of interest to declare.

\section{References}

1 Saccone G, Maruotti GM, Giudicepietro A, Martinelli P; Italian Preterm Birth Prevention (IPP) Working Group. Effect of cervical pessary on spontaneous preterm birth in women with singleton pregnancies and short cervical length: a randomized clinical trial. JAMA 2017;318(23):2317-2324. Doi: 10.1001/jama.2017.18956
2 Goya M, Pratcorona L, Merced C, et al; Pesario Cervical para Evitar Prematuridad (PECEP) Trial Group. Cervical pessary in pregnant women with a short cervix (PECEP): an open-label randomised controlled trial. Lancet 2012;379(9828):1800-1806. Doi: 10.1016/ S0140-6736(12)60030-0

3 Nicolaides KH, Syngelaki A, Poon LC, et al. A randomized trial of a cervical pessary to prevent preterm singleton birth. N Engl J Med 2016;374(11):1044-1052. Doi: 10.1056/NEJMoa1511014

4 Karbasian N, Sheikh M, Pirjani R, Hazrati S, Tara F, Hantoushzadeh S. Combined treatment with cervical pessary and vaginal progesterone for the prevention of preterm birth: A randomized clinical trial. J Obstet Gynaecol Res 2016;42(12):1673-1679. Doi: $10.1111 /$ jog. 13138

5 Cruz-Melguizo S, San-Frutos L, Martínez-Payo C, et al. Cervical pessary compared with vaginal progesterone for preventing early preterm birth: a randomized controlled trial. Obstet Gynecol 2018;132(04):907-915. Doi: 10.1097/AOG.0000000000002884

6 Suhag A, Berghella V. Cervical cerclage. Clin Obstet Gynecol 2014; 57(03):557-567. Doi: 10.1097/GRF.0000000000000044

7 Cross RG. Treatment of habitual abortion due to cervical incompetence. Lancet 1959;274:127. Doi: 10.1016/S0140-6736(59) 92242-1

8 Abdel-Aleem H, Shaaban OM, Abdel-Aleem MA. Cervical pessary for preventing preterm birth. Cochrane Database Syst Rev 2013; (05):CD007873. Doi: 10.1002/14651858.CD007873.pub3

9 Hui SYA, Chor CM, Lau TK, Lao TT, Leung TY. Cerclage pessary for preventing preterm birth in women with a singleton pregnancy and a short cervix at 20 to 24 weeks: a randomized controlled trial. Am J Perinatol 2013;30(04):283-288. Doi: 10.1055/s-00321322550

10 ARABIN® Cerclage Pessar perforiert. https://dr-arabin.de/produkt/ arabin-cerclage-pessar-perforiert/. Accessed September 25, 2018

11 Pessário Parto Prematuro. 2015. http://www.ingamed.com.br/produtos-detalhe/51/pessario-parto-prematuro. Accessed September 25, 2018

12 Daskalakis G, Zacharakis D, Theodora M, et al. Safety and efficacy of the cervical pessary combined with vaginal progesterone for the prevention of spontaneous preterm birth. J Perinat Med 2018; 46(05):531-537. Doi: 10.1515/jpm-2017-0009

13 Higgins JPT, Green S. Cochrane Handbook for Systematic Reviews of Interventions Version 5.10. The Cochrane Colaboration; 2011. http:// handbook-5-1.cochrane.org/. Accessed September 15, 2018

14 Saccone G, Ciardulli A, Xodo S, et al. Cervical pessary for preventing preterm birth in singleton pregnancies with short cervical length: a systematic review and meta-analysis. J Ultrasound Med 2017;36(08):1535-1543. Doi: 10.7863/ultra.16.08054

15 Alfirevic Z, Owen J, Carreras Moratonas E, Sharp AN, Szychowski JM, Goya M. Vaginal progesterone, cerclage or cervical pessary for preventing preterm birth in asymptomatic singleton pregnant women with a history of preterm birth and a sonographic short cervix. Ultrasound Obstet Gynecol 2013;41(02):146-151. Doi: 10.1002/uog. 12300

16 Norman JE, Marlow N, Messow CM, et al; OPPTIMUM study group. Vaginal progesterone prophylaxis for preterm birth (the OPPTIMUM study): a multicentre, randomised, double-blind trial. Lancet 2016; 387(10033):2106-2116. Doi: 10.1016/S0140-6736(16)00350-0

17 Hassan SS, Romero R, Vidyadhari D, et al; PREGNANT Trial. Vaginal progesterone reduces the rate of preterm birth in women with a sonographic short cervix: a multicenter, randomized, doubleblind, placebo-controlled trial. Ultrasound Obstet Gynecol 2011; 38(01):18-31. Doi: 10.1002/uog.9017

18 Arabin B, Halbesma JR, Vork F, Hübener M, van Eyck J. Is treatment with vaginal pessaries an option in patients with a sonographically detected short cervix? J Perinat Med 2003;31(02):122-133. Doi: 10.1515/JPM.2003.017 